$$
\text { Conf-940843i-16 }
$$

UCRI-JC-118999

inter

Engineering Design of the ITER RF Systems

M. Makowski

Lawrence Livermore National Laboratory

Livermore, $\mathrm{CA}$

G. Bosia

European Commission

European Community

T. Nagashima

Japan Atomic Energy Research Institute

Tokai-Mura, Ibaraki, Japan

D. Remsen

General Atomics

San Diego, CA

This paper was submitted to

18th Symposium on Fúsion Technology

Karlsruhe, Germany

August 22-26, 1994

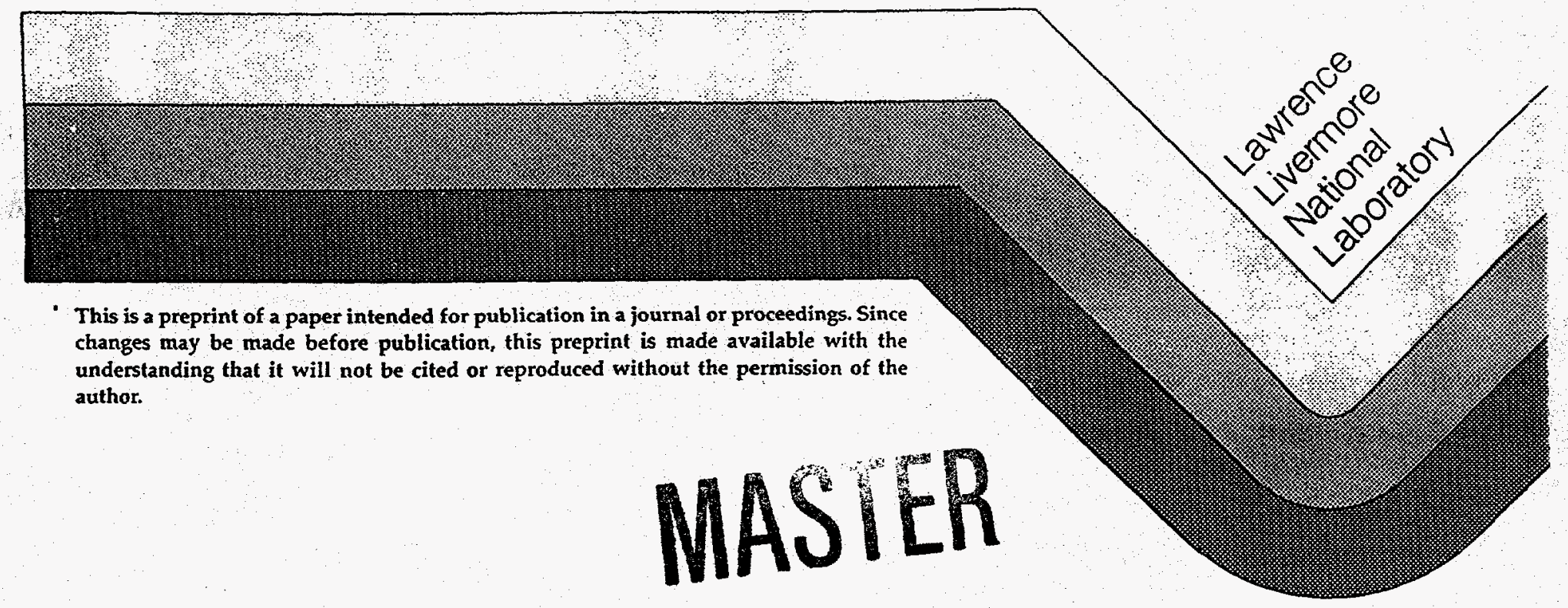




\section{DISCLAIMER}

This report was prepared as an account of work sponsored by an agency of the United States Government. Neither the United States Government nor any agency thereof, nor any of their employees, make any warranty, express or implied, or assumes any legal liability or responsibility for the accuracy, completeness, or usefulness of any information, apparatus, product, or process disclosed, or represents that its use would not infringe privately owned rights. Reference herein to any specific commercial product, process, or service by trade name, trademark, manufacturer, or otherwise does not necessarily constitute or imply its endorsement, recommendation, or favoring by the United States Government or any agency thereof. The views and opinions of authors expressed herein do not necessarily state or reflect those of the United States Government or any agency thereof. 


\section{DISCLAIMER}

Portions of this document may be illegible in electronic image products. Images are produced from the best available original document. 


\title{
Engineering Design of the ITER RF Systems*
}

\author{
M. Makowski, G. Bosia, T. Nagashima, D. Remsen \\ ITER Garching Joint Work Site, Boltzmannstr. 2 \\ 85748 Garching, Germany
}

Parallel conceptual design efforts for auxiliary heating systems on ITER are being carried out in both the electron cyclotron range of frequencies (ECRF) and ion cyclotron range of frequencies (ICRF). These systems are required to deliver a minimum of $50 \mathrm{MW}$ of $\mathrm{CW}$ power to the plasma for the primary purpose of heating and the secondary purpose of current drive. Current designs of the two systems are presented and the primary design issues are discussed.

\section{Introduction}

The primary purpose of the auxiliary power system is to provide the heating power necessary to reach ignition. An absorbed power of $50 \mathrm{MW}$ is found to be adequate to ignite ITER plasmas under a variety of assumptions. The duration for which auxiliary heating is required depends on the scenario, but is typically in the range $50-100 \mathrm{~s}$. CW capability is desirable since it is of interest in determining the effectiveness of auxiliary power to stabilize the burn and in the study of high-Q scenarios.

A second purpose of the auxiliary power system is to enable exploration of current-drive scenarios for discharge control and extensions of the pulse length. However, the experimental basis for such scenarios is not well-established and therefore specific requirements cannot as yet be set. The approach taken is to note the development of steady-state concepts and to ensure that the auxiliary power system can be adapted to the requirements as they arise. For example, high bootstrap current regimes typically require a relatively small driven current near the axis. The auxiliary power system should be compatible with driving such peaked current profiles.

Both ICRF and ECRF are capable of achieving these goals 1 . The fundamental requirement for both systems is to deliver 50 MW of CW power to the plasma for heating and current-drive applications. The systems are also required to be upgradable to $100 \mathrm{MW}$. The characteristic features of both the ICRF and ECRF Systems have been developed in accordance to the recommendations of the Technical Committee Meeting on RF Heating and Current Drive, held in Garching in October 1993.

\section{ECRF System Design}

The ECRF system design minimizes the impact of the antenna on the blanket/shield while achieving the physics requirements. Power is injected into ITER by quasi-optical techniques. This method at once achieves a high injected power density and minimal impact on the shield/blanket. The design delivers $50 \mathrm{MW}$ through an $0.15 \mathrm{~m}^{2}$ aperture at a power density in excess of $300 \mathrm{MW} / \mathrm{m}^{2}$. Two ports are thus required for a $100 \mathrm{MW}$ system.

\subsection{ECRF Antenna}

A diagram of the ECRF antenna module. is shown in Fig. 1. Electron Cyclotron wave power is supplied to the optical transmission components by an array of 60 corrugated waveguides each carrying approximately 1.0 MW of power. Each in-vessel waveguide run begins at the primary containment boundary formed by a barrier wirdow. The direction of the waveguide run is changed twice with miter bends. The final segment of each waveguide is terminated and forms a radiating aperture which illuminates the first optic (Mirror 1).

Mirror 1 collects and focuses the incident power through an aperture in the first wall

*This work was performed under the auspices of the U.S. Department of Energy by Lawrence Livermore National Laboratory under contract No. W-7405-Eng-48. 


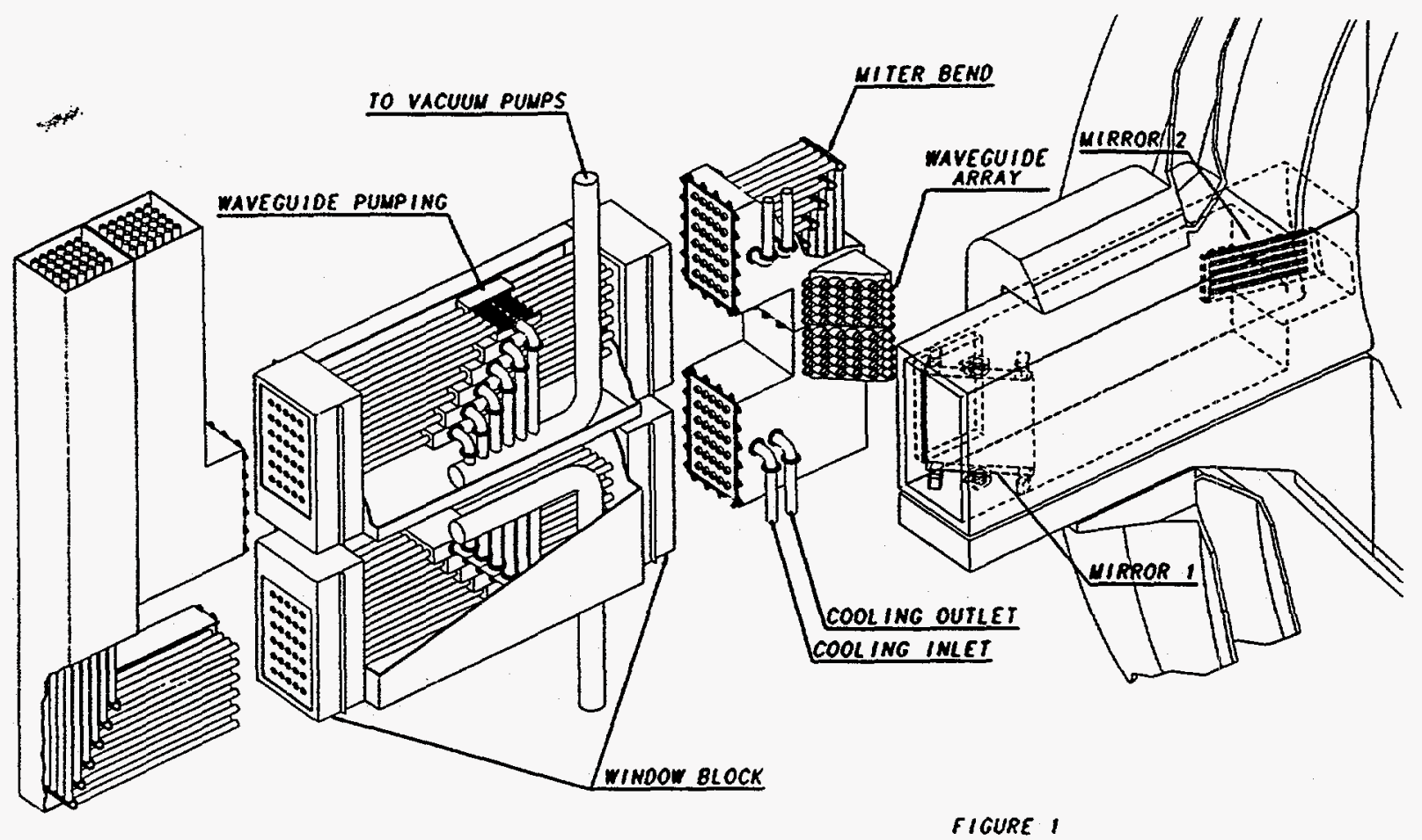

portion of the antenna module. This configuration, in which injection of the power is nearly perpendicular, is used for start-up and heating. Alternatively, Mirror 1 can be rotated to direct the power at Mirror 2. The second optic is inclined toroidally and injects the power at an angle of $35^{\circ}$ for current drive applications ${ }^{\mathbb{I}}$.

The mirrors both reflect the nominal 50 MW of launched power of which $0.3 \%$ and $0.8 \%$ are ohmically dissipated respectively in the first and second optics. Ohmic loss in the second mirror is higher than in the first due to the large angle of incidence. Nuclear heating and plasma radiation also contribute to the heat load on both optics requiring they be cooled. Since the first optic is recessed within the port the two sources of heat are substantially reduced relative to their values at the first wall. In the case of the second optic, the sources are spatially dependent due to the shielding effect of the blanket and the orientation of the optic relative to the aperture. The nuclear heating varies by a factor of six along the length of the mirror and the radiative and particle heat fluxes by a factor of ten.

It is not anticipated that maintenance will be required more often than that for the tokamak. Provisions are included for the remote handling of all in-vessel components, particularly the two optics. Each may be removed independently from the antenna module. Mirror 2 can be extracted through the vacuum vessel. Mirror 1 can be withdrawn through the cryostat. The entire module, can also be withdrawn through the cryostat.

The remainder of the antenna module is primarily structural and serves two functions; first wall and supplemental shield. The portion of the module facing the plasma forms part of the first wall and must perform to the specifications and standards established for that component. The design used for the first wall should be readily adaptable to the module. A difference is that the presence of the aperture in the module first wall introduces stresses during a disruption which a continuous first wall does not experience.

The loss of shielding presented by the apertures in both the blanket and the vacuum vessel must be compensated for. This is accomplished though the use of thick module 
side walls. (Additional shielding is provided by the port walls). For the small apertures being proposed, the amount of supplemental shielding is estimated to be small $(50 \mathrm{~cm}$ total $)$.

\subsection{ECRF Sources and Transmission System}

Recent results provide confidence that gyrotrons generating $1 \mathrm{MW}$ of $170 \mathrm{GHz} \mathrm{CW}$ power in a linearly polarized Gaussian-like output mode with $50 \%$ efficiency will be available for ITER. The tubes and supplies will be located in a single hall for convenient and efficient distribution of services and supplies.

The evacuated ex-vessel transmission system begins at the gyrotron and ends at the vacuum vessel barrier window. The Gaussianlike output mode of the gyrotron is converted into the $\mathrm{HE}_{11}$ waveguide mode by a series of RF conditioning optics. A nominal $1 \mathrm{MW} \mathrm{CW}$ vacuum waveguide run is comprised of the following sub-components: miter bends (10), corrugated waveguide (100 meter), barrier windows (2), DC break (1), expansion segments (10), vacuum pumping sections (3), beam conditioning optics, dummy load(1), maintenance valve (1), double isolation valve (1).

The waveguides will be bundled in groups of 6 tubes to simplify assembly and alignment of the system. Common cooling and vacuum services are supplied to each bundle.

\section{ICRF Antenna Design}

The system is designed to provide reliable, efficient and inexpensive plasma heating and to drive the central seed current in high bootstrap current steady-state ITER scenarios ${ }^{1,2}$.

Tritium second harmonic (60 MHz) and deuterium fundamental ( $43 \mathrm{MHz}$ ) are the most suitable resonant frequencies for central heating at a toroidal field of $6 \mathrm{~T}$. Current drive requirements extend the frequency range down to $20 \mathrm{MHz}$ (below all competitive ion resonant frequencies). A relatively wide frequency range (20 to $70 \mathrm{MHz}$, with a desirable extension to 85 $\mathrm{MHz}$ ), has therefore been chosen.

A multi-resonant stripline antenna, short circuited at both ends, having an electrical length approximately equal to $\lambda / 2$ at the lowest frequency used ( $20 \mathrm{MHz}$ ), and asymmetrically fed at an intermediate point is being evaluated. This configuration provides a good power transfer efficiency in most of the frequency ranges of interest, has self supporting current straps and feeders, and features self tuning properties. The antenna is $0.5 \mathrm{~m}$ wide and $\sim 3$ $m$ long in order to increase plasma coupling. The RF power density is intentionally low $(<1.5$ $\mathrm{MW} / \mathrm{m}^{2}$ ) at the first wall.

The total installed power is $72 \mathrm{MW}$, delivered by 36 current straps, individually powered and tuned, toroidally grouped in two sub-arrays of 18 . The arrays are located (Fig 2) on the low field side and integrated in the lower section of the outer shield/blanket, below the plasma mid plane, with Vacuum Transmission Lines routed through 6 radial ports. All antennas are removable through the same ports.

Most of 1994 activity has been dedicated to the in-vessel components (Antenna array(s) and Vacuum Transmission Lines) design and analysis. A 3D CAD model of the whole antenna array and feeders has been developed with different Faraday Screen (FS) design options, in order to carry out antenna configuration studies, define the interfaces with the shield-blanket and the remote handling removal procedures.

A removal scheme for the antenna, together with the whole blanket segment is now available. It appears to be simpler than the maintenance of individual antenna components such as Faraday screen sections. The scheme is also applicable to the removal of the Test Blanket Module. The shield/blanket around the antenna has been re-designed in order to suit the antenna geometry, provide coolant to the FS and ease the antenna removal.

The ICRF antenna plasma facing components (Faraday screen and current strap) are part of the ITER first wall and are submitted to very similar thermal and electrodynamic loads. The antenna Faraday screen must be designed to carry the full disruption currents and not constitute a large toroidal or poloidal electrical discontinuity, to prevent stress concentration at the shield-blanket interface. 


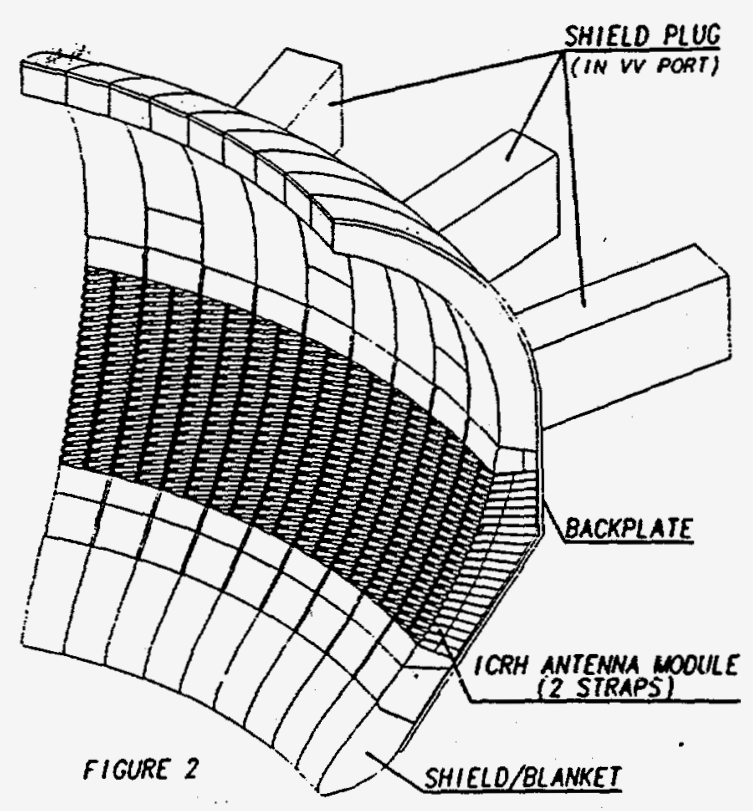

The structural properties of the main Antenna components (Faraday screen, current strap, FS supports) are presently being analysed under ITER thermal and electrodynamic loads for different first wall materials, dimensions, and thickness. Schemes for joining Faraday screen elements have been studied and will be submitted for analysis to determine stress concentrations.

Acceptable thermal stresses of the Faraday screen elements $(-150 \mathrm{MPa})$ are deduced from 3D finite element analysis with 316 SS $3 \mathrm{~mm}$ thick as structural material (at a surface loading of $0.5 \mathrm{MW} / \mathrm{m}^{2}$ and neutron loading of $10 \mathrm{MW} / \mathrm{m}^{3}$ ), provided that both poloidal and toroidal thermal expansions (in the $\mathrm{mm}$ range) are allowed. These values are further reduced if a $5 \mathrm{~mm}$ Be coating or claciaing (possibly used as first wall inateriai) is taken into account. Use of a copper alloy such as $\mathrm{Cu}-\mathrm{Zr}_{\mathrm{r}}-\mathrm{Cr}_{\mathrm{r}}$ further reduces the stresses. Analysis shows that in the FS, surface loading is the most important source of thermal stress.

Electrodynamic stresses have also been computed on a 3D antenna model after 2D analysis was used to dimensionally define the FS elements and supports. For a $3 \mathrm{~mm}$ thick SS wall the maximum bending stress of $\sim 100 \mathrm{MPa}$ are found for a surface load of $1 \mathrm{MPa}$. With copper alloy, stress levels typically $15 \%$ higher are found. Stresses arising from bending moments due to the interaction of the FS current with the toroidal field are in both cases a factor 2 lower, provided that the FS element is in normal operation and aligned with the local field (pitch angle 15\%) A self consistent evaluation of eddy current distribution in disruption scenarios is being performed.

Results indicate that the ITER ICRF antenna will need a "thick" Faraday screen, (> $50 \mathrm{~mm}$ OD tubing), an unusual situation in present day tokamaks. The impact of a thick FS on the antenna radiation pattern and power transfer efficiency needs to be evaluated.

In conclusion, the problems linked to the integration of an ICRF array in ITER blanket have been considered, as a preparatory work to a more detailed analysis performed by the Home Teams. Future work will be dedicated to the definition of out of vessel components.

\section{REFERENCES}

1. G. Bosia, et. al, $21^{\text {st }}$ EPS Conference on Controlled Fusion and Plasma Physics, June 27 - July 1, 1994, Montpellier, France.

2. Bhatnagar, V., Jacquinot, J., JET Report $P(93) 76$.

\section{ACKNOWLEDGEMENT}

This report was prepared as an account of work performed within the ITER Joint Central Team under the Agreement among the European Atomic Energy Community, the Government of Japan, the Government of the Russian Federation, and the Government of the United States of America on Co-operation in the Engineering Design Activities for the International Thermonuclear Experimental Reactor ("ITER EDA Agreement") under the auspices of the International Atomic Energy Agency (IAEA).

The significant contributions of the Home Teams are gratefully acknowledged and appreciated. 